\title{
ACADEMIC ENTREPRENEURSHIP: A FOCUS ON ENTREPRENEURIAL ALERTNESS, ATTITUDES, NORMS AND BELIEFS
}

\section{B. Urban}

Graduate School of Business and Management

University of Witwatersrand

Johannesburg, South Africa

e-mail: boris.urban@wits.ac.za

\section{ABSTRACT}

Considering the increasing importance of the "third mission" to universities, several scholars recognise that academic entrepreneurship is required for successful commercialisation of research and venture start-ups. While several universities in South Africa have embarked on establishing technology transfer offices, the potential effect of academic entrepreneurship has yet to be realised. This study aims to provide insights into how an individual's entrepreneurial alertness shapes their attitudes, beliefs and norms in terms of academic entrepreneurship. Following a survey, the results show that "attitudes towards behaviour, subjective norms, and perceived behavioural control" are significantly increased when higher levels of entrepreneurial alertness are prevalent. Educators are encouraged to design curricula focused on improving entrepreneurial alertness by considering its antecedents in relation to academic entrepreneurship.

Keywords: academic entrepreneurship, entrepreneurial alertness, attitudes, subjective norms, behavioural control, universities, South Africa.

\section{INTRODUCTION}

Increasingly, researchers recognise that the "commercialisation of academic and scientific research" through entrepreneurship and university start-ups has been a source of development and innovation in several different countries (Meyer 2011, 1; Moog et al. 2015; Rothaermel, Agung and Jiang 2007, 692). The "transformative effect of academic entrepreneurship", specifically through technology transfer in developed economies such as the US, reveals that policy and legislation, such as the "University and Small Business Patent Procedures Act of 1980, the so-called Bayh-Dole Act" have been instrumental in driving such development and innovation (Aldridge et al. 2014, 821). Several other countries have also formulated guidelines and legislation to ensure the commercialisation of university generated knowledge and research (Djokovic and Souitaris 2008, 225; Sampat 2009, 3), where for instance in Europe, as a result of similar policy implementation, many countries have experienced a significant increase in university entrepreneurship activity and resultant innovations (Rothaermel et al. 2007, 691). 
Similarly, the African Union prioritises "science, technology and innovation (STI) as a catalyst for Africa's development in the next 50 years" (RSA 2014, 24). In South Africa (SA), the "Intellectual Property Rights (IPR) on Publicly Financed Research and Development Act No 51 was promulgated in 2010 as part of efforts to regulate the use of IPR emanating from government funded institutions (DST 2012) and as part of the Act, Higher Education Institutions (HEI) and Science Councils had to establish Technology Transfer Offices (TTO) to be responsible for identification, protection and commercialisation of innovations (RSA 2014)". Furthermore, over the last decade the "Department of Science and Technology (DST) has advanced a National System of Innovation (NSI) through a number of policy interventions" (CSIR 2012; DST 2012). Correspondingly, South African universities have also established commercialisation offices to take advantage of research and convert this to intellectual property (Alessandrini, Klose and Pepper 2013, 206; Beukman and Steyn 2011, 41). Initiatives such as the "Entrepreneur-in-Residence" concept have evolved at the "Council of Scientific and Industrial Research (CSIR)" (CSIR 2012), which demonstrate to some degree that academics need to be "entrepreneurial to be successful in research, teaching, engagement in practice and in the commercialisation of academic knowledge" (Agarwal and Shah 2014, 1110; Perkmann et al. 2013; Pouris 2007, 2012; Urban and Chantson 2018).

The term "academic entrepreneurship" has been conceptualised narrowly as "new enterprises started within a university setting and based on technology derived from university research" (Link, Siegel and Bozeman 2007, 641), or "the creation of new business ventures by university agents" (Meyer 2011, 1; Prodan and Drnovsek 2010, 333), with attention on the "individual scientist or researcher who typically leverages a new technology to start a venture" (Aldridge et al. 2014, 820). However, apart from "venture spin-offs", a more wide-ranging definition, includes "any activity that occurs beyond the traditional roles of teaching and research, which is innovative and comprises an element of risk, and may lead to financial rewards for the individual or the institution" (Abreu and Grinevich 2013, 409). Such a broader conceptualisation of academic entrepreneurship is suited for the purpose of this study.

Despite the mounting significance of commercialisation of research at universities and the materialisation of the "entrepreneurial university over recent years" (Agarwal and Shah 2014, 1110; Rothaermel et al. 2007, 693; Sieger and Monsen 2015, 31), universities, both in SA and globally have been slow to transform their traditional research and teaching activities to enable the commercialisation of research and technologies. Many universities are unable to create a conducive environment that supports commercialisation and "which can potentially reduce the conflict of interest between traditional and entrepreneurship efforts" (Urbano and Guerrero $2013,3)$. Additionally, in SA the support provided by TTO to academics is normally focused 
on the "identification and protection of new intellectual property, with much less focus on startup formation" (Pouris 2007; Urban and Chantson 2018, 3).

Study findings reveal that notwithstanding "the amount research funding allocated to universities and science councils, only a small percentage of research outputs are commercialised in SA" (Pouris 2012, 2; Sibanda 2009, 114). Boshoff $(2017,46)$ notes that university research in SA is "very inward-looking in terms of its beneficiaries". To add to this dilemma, not only is there a lack of extracting value from the technology commercialisation and innovation processes, but the general low rate of academic start-ups in SA has been "attributed to many institutions' preference for licensing to established companies" (Pouris and Pouris 2011, 25; Sibanda 2009, 116; Uctu and Jafta 2014, 129) and a general lack of entrepreneurial intentions (Urban and Pendame 2015, 267).

An analytical synopsis of the literature indicates that while the majority of existing studies on academic entrepreneurship have focused on the function of the university or the contextual surroundings, "the role of the academic, scientist or researcher as an agent in the academic entrepreneurial process is often neglected" (Jain, George and Maltarich 2009, 922; Urban and Chantson 2018, 5). Such an oversight is somewhat surprising given the centrality of the entrepreneurial mind-set and need for alertness in the entrepreneurship literature (Urban and Pendame 2015, 265). "Why, when and how certain individuals exploit opportunities, is a function of both the opportunity and the nature of the individual" (Urban 2017, 2). Research indicates that "while most individuals scan their environment, successful entrepreneurs may be better at discovering opportunities embedded in that environment as their alertness allows them to spot high-potential opportunities" (Gaglio and Katz 2001, 95; Tang, Kacmar and Busenitz 2012, 77).

The rationale of this study is to assess the relevance of "entrepreneurial alertness (EA)" in relation to academic entrepreneurship. The overarching framework which the study is based on is the "theory of planned behaviour (TPB)", where "the tenants of TPB are based on behavioural beliefs as determinants of attitudes, normative beliefs as determinants of social norm, and control beliefs" (Ajzen 1991, 179). While extensive studies have examined the TPB antecedents and entrepreneurial intentions link (Ajzen 2001; Armitage and Conner 2001), research on EA as a precursor to each of the TPB antecedents remains underdeveloped. It is anticipated that by examining EA through the lens of the TPB theoretical framework, "ongoing research in management, cognitive and social psychology will benefit since individual differences with respect to EA have been reported" (Baron 2006, 113; McCaffrey 2013, 893). The study adds to the academic entrepreneurship literature, as universities and research organisations are wellpositioned to improve overall "regional economic development" (Block, Thurik and Zhou 
2013, 694), and "increase science-society engagement" (Malan, Simpson and Janse van Rensburg 2015, 154; Urban and Pendame 2015, 266).

The article is organised to first stipulate the theoretical basis for the variables under study, which inform the study hypotheses. This is followed by research methods where sampling and measurement instruments are discussed. The study findings are then presented and analysed. Finally, study implications are considered in the context of educators and policy-makers.

\section{THEORETICAL OVERVIEW}

Alertness has been conceptualised to explain "entrepreneurial recognition of opportunities" (Kirzner 2009, 145) and as "a propensity to notice and be sensitive to information about objects, incidents, and patterns of behavior in the environment, with special sensitivity to make and use problems, unmet needs and interests, and novel combinations of resources" (McCaffrey 2014, 892). Prior research findings indicate that the alertness process consists is characterised by three distinct stages (Gaglio and Katz 2001; Tang et al. 2012). "Firstly, individuals constantly scan the environment to identify information or changes that have gone unnoticed by others. Secondly, individuals use association and connection in order to gather information of different qualities and use that knowledge to build new alternatives. Thirdly, individuals rely on their evaluation and judgment which includes making assessments and judgments about changes or new information and deciding whether these are in fact will lead to a potential opportunity" (Tang et al. 2012, 79).

Several studies have used this three phase model approach to study alertness and indicate that all of the stages are pivotal for opportunity recognition (Baron 2006). Kirzner $(2009,148)$ maintains that although "an individual cannot consciously trigger alertness, it will not be activated unless the individual is motivated to do so". This implies that there are certain psychological qualities or attributes, which will be beneficial or even necessary in order for an individual to be in a state of "alertness" (Urban 2017, 14).

While in the traditional entrepreneurship literature, alertness has been associated with opportunity recognition (Tang et al. 2012, 79), in terms of academic entrepreneurship, studies are emerging that have found other factors such as "career experience, education, social norms, and beliefs are useful in explaining the propensity of academics to be entrepreneurial" (Goethner et al. 2012, 629). Consequently, the TPB "as a social cognitive theory, which has been applied to analyse human intention and action" (Ajzen 2001, 29), is a useful lens through which to examine the EA of individual's attitudes, norms and beliefs in the framework of "academic entrepreneurship". In contrast to the other models, there is general support for the TPB (see, Armitage and Conner 2001), where the three antecedents of intentions have already 
been considerably supported (Ajzen 2001), and form the basis of the study hypotheses:

"Attitude to the behaviour (ATB)": ATB is the "degree to which the implementation of a particular behaviour, such as starting a new business, is favourably or unfavourably valued" (Ajzen 2001, 28). Consequently, ATB is shaped by the "expectations and beliefs about the personal impacts of expected outcomes resulting from the behaviour, that is, behavioural beliefs" (Ajzen 2001, 29). In some studies ATB has been found to be the most significant of the three predictors in terms of the TPB model (Schlaegel and Koenig 2014, 291). Correspondingly, in the academic entrepreneurship literature, it has been remarked that even though academics and scientists "may improve their reputation, earn more income and gain more satisfaction attitudes vary considerably for faculty when deciding to engage in academic entrepreneurship" (Link et al. 2007, 650). Against this backdrop of findings on intentions and relying on the precepts of the TPB, in the first instance, it is hypothesised:

- $\quad \mathrm{H} 1$ : Entrepreneurial alertness has a significant role in fostering positive attitudes towards behaviour for academic entrepreneurship

"Subjective norms (SN)": SN is the "perceived social pressure to perform a particular behaviour and is underpinned by what the individual perceives are the expectations and beliefs of influential people in his/her life towards creating a start-up" (Ajzen 2001, 29). Such prominent "people include the significant other, family, friends, colleagues, mentors or role models". Studies have also emerged which show that the presence of entrepreneurial role models can influence academics to engage in entrepreneurial activities themselves (Prodan and Drnovsek 2010, 335). Following these findings and in line with the reasoning of incorporating $\mathrm{SN}$ in the TPB model, it is expected:

- $\quad \mathrm{H} 2$ : Entrepreneurial alertness plays a significant role in fostering positive subjective norms for academic entrepreneurship

"Perceived behavioural control (PBC)": PBC refers to an "individual's perceptions of his/her ability to execute a given behaviour (Ajzen 2001, 29). It is governed by the beliefs about the perceived factors that facilitate or hinder execution of the behaviour, that is, control beliefs" (Ajzen 2001, 30). In terms of "academic entrepreneurship, findings reveal that insofar entrepreneurial activity may be measured with a variety of markers, such as the number of patents and the number of licenses and start-up ventures and are only possible if individual 
faculty members perceive that this behaviour is desirable" and act accordingly (Prodan and Drnovsek 2010, 336). In other words, individuals must perceive they have control to influence outcomes and have a positive PBC. Consequently, by building on this stream of research it is hypothesised:

- H3: Entrepreneurial alertness plays a significant role in fostering positive perceived behavioural control for academic entrepreneurship

\section{RESEARCH DESIGN}

The study was based on a sample of academics and research scientists at universities and science councils in SA. The present investigation forms part of a larger ongoing study on academic entrepreneurship (Urban and Chantson 2018; Urban and Pendame 2015) and utilises the same study population consisting of public universities distributed across several provinces of SA (Universities SA 2016). In terms of a "science council, which is a statutory research body, there are eight in SA, their central purpose is to conduct directed research and development, and they are largely publicly-funded" (Scholes et al. 2008, 435). The study was based on the "Council of Scientific and Industrial Research (CSIR)" (CSIR 2012).

As no comprehensive sampling frame is available on "academic entrepreneurship" activity, a convenience sampling method was used to source respondents to represent the "three largest provinces across SA". This approach ensured "sufficient variability and a degree of regional representativeness" (Walter, Parboteeah and Walter 2013, 176). Considering the aim of the study, which is focused on individual perceptions, a quantitative approach was used which was survey-based as it is "relatively common in the investigation of basic cognitive, behavioural and attitude questions relating to entrepreneurship" (Urban and Pendame 2015). The study followed all ethical standards for research "without direct contact with human or animal subjects". Ethical concerns were taken into consideration by safeguarding the respondent's anonymity. The study purpose was explained to participating respondents, as well as their rights and protections which was made explicit and explained at the start of the data collection process. Respondent's privacy and confidentiality was recognised throughout the research data collection processes. After a period of two weeks of surveying, 164 full questionnaires were obtained and used for statistical analyses.

\section{Instrument}

The questionnaire was based on the initial theoretical overview and in line with the findings on the TPB antecedents. Suitable measures were identified from the literature to ensure that these 
items were aligned with the study hypotheses.

The first part of the instrument consisted of demographic questions of respondents and included: Gender, age, and field of expertise. The "propensity of scientists and academics to start a firm has been shown to vary widely from one scientific field to another" (Perkmann et al. 2013, 440), hence the inclusion of this variable as a control factor. The other control variables included: "Gender (dummy variables $1=$ male, $0=$ female), age categories $(21-30 ; 31$ to 40; 41 to $50 ; 51$ to $60 ; 60+$ ), field of expertise (agricultural sciences; medical and life sciences; natural sciences; engineering and technology; and other)".

The second part of the instrument was concerned with theTPB model and measured three dimensions in terms of the following: ATB (5 items), SN (3 items), and PBC (6 items). Several items were treated as "reverse statements, where it has been noted that the benefits of including reversed items are to control for acquiescence and to disrupt non-substantive patterns of responding. Furthermore, relying on multi-item variables reduces potential measurement error" (Cooper and Emory 1995, 445).

The third part of the instrument was concerned with EA and was operationalised on the basis of prior studies where construct validity has been demonstrated (Tang et al. 2012). Nine items were used to measure EA and all the questions were adapted to reflect the academic entrepreneurship domain. Sample items included "I see links between seemingly unrelated pieces of information" and "I can distinguish between profitable opportunities and not-soprofitable opportunities in terms of commercialisation". All questions were closed-ended and used with a "7-point Likert scale where $1=$ total disagreement and 7= total agreement".

\section{Data analysis}

Because of the nature of the data collection method - survey based, the "potential problem of common-method bias (Podsakoff, MacKenzie, and Podsakoff 2012, 540) was counteracted with a number of procedural steps". The questionnaire "featured a counter-balanced question order and the respondents were requested to be honest in their responses while assuring responses remain completely anonymous". Likewise, a "consistent scale format was used, where scale items have been tried and tested and the scale included negative and positive statements" (Cooper and Emory 1995, 356). Furthermore, all measures were subjected to factor analysis and reliability testing. Hypotheses were tested with correlational and regression analyses.

\section{RESULTS}

In terms of demographic profiles, there were slightly more male (54\%) than females (45\%), and 
mostly situated (55\%) in the 41-50 age category, while the remainder were approximately equally distributed between the 21 to 30 , and 31 to 40 , and 51 to 60 age groups. These results resonate with past studies which show that "older researchers already have more of an established research career and solid academic reputation and are therefore less motivated than their younger colleagues to re-direct their focus to academic entrepreneurship" (Prodan and Drnovsek 2010, 333). In terms of the field of expertise, most respondents (53\%) were from the faculty of "Science and Technology", while 22 per cent were from "Engineering", 12 per cent from "Medical and Health Sciences", 10 per cent from "Agricultural Sciences". To determine the "effects of single control variables on EA in isolation to other control variables, comparisons of means tests were conducted" (Cooper and Emory 1995, 412) which did not "reveal any statistical differences" in EA on any of the control variables, and "subsequently these control variables were not used in further analyses".

Construct validity was tested using the "Kaiser-Meyer-Olkin (KMO) measure of sampling adequacy and Bartlett's test of sphericity" was used. For the total sample, the "KMO measure of sampling adequacy" was 0.82 (higher the threshold of 0.6 ), with a significant "Bartlett's test of sphericity" ( $\mathrm{p} \leq 0.001)$; both indicators providing support for factorisation of variables (Cooper and Emory 1995). "Exploratory Factor Analysis (EFA)" was used with the "principal axis factoring method, where eigenvalues greater than one and factor loadings of $\geq 0.5$ were regarded as significant" (Cooper and Emory 1995, 311). After several iterations, based on the EFA results the following factors were extracted and retained which explained 79 per cent of total variance: "Factor $1=$ TPB (ATB); Factor $2=$ TPB $(\mathrm{SN})$; Factor $3=$ TPB $(\mathrm{PC})$; Factor $4=$ EA". To test for scale reliability, Cronbach's alpha coefficient was calculated and results proved reliable on all four factors (>.70) (Cooper and Emory 1995).

For an overview of the descriptive statistics, see Table which shows the "mean scores, standard deviations, and Pearson correlation coefficients" for each of the factors. The results indicate that on average factor mean scores were above mid-point, with the highest and lowest mean score observed for ATB and SN respectively. Table 1 further shows that all the factors correlated positively and significantly with EA, where the highest coefficient was for ATB and EA $(r=0.79, p \leq 0.001)$. These patterns of correlations suggest adequately high levels of associations between the factors and justify conducting regression analyses.

In line with the study hypotheses, the regression model focused on the effect of EA on $\mathrm{ATB}, \mathrm{SN}$ and PBC, respectively. Table 2, in terms of summary results shows an overall significant $F$ value $(4.131)$ and associated beta weight of $7.521(\mathrm{p}<.001)$. An adjusted $\mathrm{R}^{2}$ of 0.2444 means that this model explains 22.4 percent variance in terms of EA's effect on ATB, SN and PBC. H1 was supported where it was predicted that EA plays a significant role in 
Table 1: Correlation matrix and descriptive statistics

\begin{tabular}{|c|c|c|c|c|}
\hline Factors & 1 & 2 & 3 & 4 \\
\hline 1. $\mathrm{EA}$ & 1.00 & & & \\
\hline 2. ATB & $.79^{\star \star \star}$ & 1.00 & & \\
\hline 3. $\mathrm{SN}$ & $.69^{\star \star \star}$ & $.65^{\star \star *}$ & 1.00 & \\
\hline 4. $\mathrm{PBC}$ & $.68^{* \star *}$ & $.68^{* \star *}$ & $.56^{* \star}$ & 1.00 \\
\hline $\begin{array}{l}\text { Mean } \\
\text { Std. Dev. }\end{array}$ & $\begin{array}{l}5.89 \\
1.01\end{array}$ & $\begin{array}{l}6.01 \\
1.02\end{array}$ & $\begin{array}{l}5.66 \\
0.89\end{array}$ & $\begin{array}{l}5.88 \\
0.96\end{array}$ \\
\hline
\end{tabular}

Note: ${ }^{* *}=p<.01 ;{ }^{* * *}=p<.001$.

fostering ATB in the realm of academic entrepreneurship $(\beta=0.197 ; p=0.089)$. H2 was supported where it was predicted that EA plays a significant role in fostering $\mathrm{SN}$ in the realm of academic entrepreneurship $(\beta=0.216 ; \mathrm{p}=0.001)$. H3 was supported where it was predicted that EA plays a significant role in fostering $\mathrm{PBC}$ in the realm of academic entrepreneurship $(\beta$ $=0.125 ; \mathrm{p}=0.159)$.

Table 2: Summary regression results

\begin{tabular}{|l|c|c|}
\hline \multicolumn{3}{|c|}{ Model 1 } \\
\hline & Beta $(\beta)$ & p-value \\
\hline Constant & 2.760 & $0.000^{\star * *}$ \\
\hline Entrepreneur Alertness & 0.162 & $0.077^{*}$ \\
\hline Attitude towards behaviour & 0.197 & $0.089^{*}$ \\
\hline Subjective norms & 0.216 & $0.001^{* * *}$ \\
\hline Perceived behavioural control & 0.125 & $0.159^{*}$ \\
\hline Model statistics & & \\
\hline $\mathrm{R}^{2}$ & 0.268 & \\
\hline Adjusted $\mathrm{R}^{2}$ & 0.244 & \\
\hline $\mathrm{F}(4.131)$ & $7.521^{* * *}$ & \\
\hline \multicolumn{2}{|c|}{ Note: $\beta=$ standardized effect: $^{*}=p<.01 ;{ }^{* * *}=p<.001}$.
\end{tabular}

\section{DISCUSSION AND CONCLUSIONS}

The study results successfully demonstrate the positive stimulus of EA in the academic entrepreneurship context. Study findings reveal that EA positively influences the "attitude to the behaviour (ATB), subjective norms ( $\mathrm{SN}$ ) and perceived behavioural control (PBC)" of respondents engaged in academic entrepreneurship. The positive and significant nature of these findings provides support for the study hypotheses and yields a modest input to the growing knowledge-base which is evolving in the academic entrepreneurship domain.

Academic entrepreneurship is gaining traction as it is acknowledged that universities "do not only engage in research and teaching, but are increasingly active in their so-called 'third mission', which is why they are focused on commercialisation of research and have a concern 
with wider economic development issues" (Meyer 2011, 5). Consequently, focusing on entrepreneurial alertness and its influence on behavioural beliefs of attitudes, normative beliefs, and control beliefs (Ajzen 1991) is important, as researchers (Baron 2006) understand that in order to productively engage in commercialisation activities and start-ups, entrepreneurship is required. Building on in this research direction the present study extends existing theory by considering EA and its important role in shaping the ATB, SN and PBC of study respondents. Prior research findings focused on entrepreneurial intentions, find " $\mathrm{PBC}$ to be main determinant of intentions, with ATB and SN playing supporting roles" (Schlaegel and Koenig 2014). Contrastingly, the present study focused on EA in terms of all three of the TPB antecedents and found positive relationships.

The study findings link with prior research which finds that university mechanisms and the inducements are often employed to try and 'transform academics' behaviour into entrepreneurial acts" (Block et al. 2013, 695). An important aspect of such entrepreneurial acts is EA, which should be nurtured and fostered to increase academic entrepreneurship. However, if the institutions' "intellectual property and promotion policies are not aligned to guide faculty on desired outcomes of commercialisation, licensing and spin-offs, institutions will experience reluctance in participation in such activities by academics" (Renault 2006, 229). Furthermore, while researchers argue that "a reward system is one of the most effective strategic actions to motivate for academic entrepreneurship and assist in creating an image of academic entrepreneurship as a desirable career path" (Link et al. 2007, 642), it is the antecedents of ATB, SN and PBC (Ajzen 1991) which affect such desirability.

Research in general on attitude and academic researchers show positive findings in terms of the "influence of linkages with industry on academic activities, where it is the informal factors (e.g., attitudes, role models) that have a higher influence on university entrepreneurial activity than formal factors (e.g., support measures, education and training)" (Sieger and Monsen 2015). EA is often a source of creativity and also depends, in part, on whether "an individual exploits the opportunity once it has been identified which is a result of developing their entrepreneurial capabilities" (McCaffrey 2014, 894). Such studies resonate with the literature on EA, where the interplay between external (e.g., social norms) and internal factors (e.g., alertness) elucidate, "why some people and not others exploit opportunities" (Baron 2006, 109).

Furthermore, the study results share commonality with former research that indicates how relevant SN are to academic entrepreneurship, where academic scientists are said to "mimic the average behaviour of departmental work colleagues when deciding to engage in entrepreneurship, which means that academic scientists compare themselves with relevant 
others who are their departmental peers" (Perkmann et al. 2013). This means that if entrepreneurship is valued in an academic departmental context, more entrepreneurial intentions and behaviour may be anticipated as a result of the positive SN.

The results hold several consequences for managers in HEI. Managers at universities encouraging entrepreneurship need to understand how each of the TPB antecedents in terms of $\mathrm{ATB}, \mathrm{SN}$ and $\mathrm{PBC}$ are shaped by EA. Managers are encouraged to provide training and incentives to foster such alertness. In this regard educators could develop entrepreneurial skills training programmes to improve levels of EA where the focus would be on the alertness process, namely in terms of the elements of "scanning and search, association and connection, and evaluation and judgment" (Tang et al. 2012). Increasing levels of EA is equally important for university collaborations, especially international collaborations, as alert individuals can spot opportunities in "knowledge transfer pipelines that connect local firms and global research networks" (Goethner et al. 2012, 630).

Study limitations relate to the "cross-sectional nature of the study", where future research could test whether EA endures over time and leads to the actual behaviour of commercialisations and venture start-ups at universities. Another limitation is the "ability to generalize the study findings" across universities since a non-probability convenience sampling method was employed. Scholars are encouraged to expand on the present study and explore EA by examining potential mediating and moderating effects. Researchers could examine the function of national research funding incentives and grants and their efficacy in influencing EA in terms of academic entrepreneurship.

\section{REFERENCES}

Abreu, M. and V. Grinevich. 2013. The nature of academic entrepreneurship in the UK: Widening the focus on entrepreneurial activities. Research Policy 42(2): 408-422.

Agarwal, R. and S. K. Shah. 2014. Knowledge sources of entrepreneurship: Firm formation by academic, user and employee innovators. Research Policy 43(7): 1109-1133.

Ajzen, I. 2001. Nature and operation of attitudes. Annual Review of Psychology 52(1): 27-58.

Ajzen, I. 1991. The theory of planned behaviour. Organizational Behaviour and Human Decision Processes 50(1): 179-211.

Aldridge, T. T., D. Audretsch, S. Desai and V. Nadella, V. 2014. Scientist entrepreneurship across scientific fields. The Journal of Technology Transfer 39(6): 819-835.

Alessandrini, M., K. Klose and M. S. Pepper. 2013. University entrepreneurship in South Africa: Developments in technology transfer practices. Innovation: Management, Policy and Practice 15(2): 205-214.

Armitage, C. J. and M. Conner. 2001. Efficacy of the theory of planned behaviour: a meta-analytic review. British Journal of Social Psychology 40(4): 471-499.

Baron, R.A. 2006. Opportunity recognition as pattern recognition: how entrepreneurs "connect the dots" to identify new business opportunities. The Academy of Management Perspectives 20(1): 104- 
119.

Beukman, E. and H. Steyn. 2011. Phasing technology transfer projects for sustainable socio-economic development. The South African Journal of Industrial Engineering 22(2): 40-53.

Block, J. H., R. Thurik and H. Zhou. 2013. What turns knowledge into innovative products? The role of entrepreneurship and knowledge spillovers. Journal of Evolutionary Economics 23(5): 693-718.

Boshoff, N. 2017. South African corresponding authors on perceived beneficiaries and the nature of university research. South African Journal of Higher Education 31(3): 46-62.

Cooper, D. R. and C. W. Emory 1995. Business research methods. Chicago: Irwin.

CSIR. 2012. Council for Scientific and Industrial Research. http://www.techtransfer.csir.co.za/ wpcontent/uploads/2012/07/CSIR-Entrepreneurs-in-residence-EIR-brief-overview.pdf (Accessed 21 April 2016).

Djokovic, D. and V. Souitaris. 2008. Spinouts from academic institutions: A literature review with suggestions for further research. Journal of Technology Transfer 33(3): 225-247.

DST. 2012. Department of Science and Technology. Ministerial Review Committee on Science, Technology and Innovation Landscape in South Africa: Final report. Pretoria: Government Printer.

Gaglio, C. M. and J. Katz. 2001. The psychological basis of opportunity identification: entrepreneurial alertness. Journal of Small Business Economics 16(1): 95-111.

Goethner, M., M. Obschonka, R. K. Silbereisen and U. Cantner. 2012. Scientists' transition to academic entrepreneurship: economic and psychological determinants. Journal of Economic Psychology 33(3): 628-641.

Jain, S., G. George and M. Maltarich. 2009. Academics or entrepreneurs? Investigating role identity modification of university scientists involved in commercialization activity. Research Policy 38(6): 922-935.

Kirzner, I. M. 2009. The alert and creative entrepreneur: A clarification. Small Business Economics 32(2): 145-152.

Link, A. N., D. S. Siegel and B. Bozeman. 2007. An empirical analysis of the propensity of academics to engage in informal university technology transfer. Industrial and Corporate Change 16(3): 641-655.

Malan, N., Z. Simpson and N. Janse van Rensburg. 2015. Driving responsible research and innovation: Science, society and the energy movement. South African Journal of Higher Education 31(5): $154-171$.

McCaffrey, M. 2014. On the theory of entrepreneurial incentives and alertness. Entrepreneurship Theory and Practice 38(8): 891-911.

Meyer, G. D. 2011. The reinvention of academic entrepreneurship. Journal of Small Business Management 49(1): 1-8.

Moog, P., A. Werner, S. Houweling and U. Backes-Gellner. 2015. The impact of skills, working time allocation and peer effects on the entrepreneurial intentions of scientists. Journal of Technology Transfer 40(3): 493-511.

Perkmann, M., V. Tartari, M. McKelvey, E. Autio, A. Broström, P. D’Este, R. Fini, R. Geuna, R. Grimaldi, A. Hughes, S. Krabel, M. Kitson, P. Llerena, P. Lissoni, A. Salter and M. Sobrero. 2013. Academic engagement and commercialisation: A review of the literature on university-industry relations. Research Policy 42(2): 423- 442.

Podsakoff, P. M., S. B. MacKenzie and N. P. Podsakoff. 2012. Sources of method bias in socail science research and recommendations on how to control it. Annual Review of Psychology 63(4): 539569.

Pouris, A. 2012. Science in South Africa: The dawn of a renaissance? South African Journal of Science 108(7/8): 1-6.

Pouris, A. 2007. Technology transfer and diffusion capacity and potential in South Africa's public 
universities - survey 2007. Pretoria: Higher Education South Africa-HESA.

Pouris, A. and A. Pouris. 2011. Patents and economic development in South Africa: Managing intellectual property rights. South African Journal of Science 107(11/12): 24-33.

Prodan, I. and M. Drnovsek. 2010. Conceptualizing academic-EI: An empirical test. Technovation 30(56): $332-347$.

Renault, C. S. 2006. Academic capitalism and university incentives for faculty entrepreneurship. Journal of Technology Transfer 3(2): 227-239.

Rothaermel, F. T., S. D. Agung and L. Jiang. 2007. University entrepreneurship: A taxonomy of the literature. Journal of Industrial and Corporate Change 16(4): 691-791.

RSA. 2014. Republic of South Africa. Proclamation by the President of the Republic of South Africa Number 43. Government Gazette Number 37817. Pretoria: Government Printer.

Sampat, B. N. 2009. The Bayh-Dole model in developing countries: Reflections on the Indian Bill on publicly funded intellectual property. Policy Brief 54. California, US: International Centre for Trade and Sustainable Development.

Schlaegel, C. and M. Koenig. 2014. Determinants of entrepreneurial intent: A meta-analytic test and integration of competing models. Entrepreneurship Theory and Practice 38(2): 291-332.

Scholes, R. J., F. Anderson, C. Kenyon, J. Napier, P. Ngoepe, B. van Wilgen and A. Weaver. 2008. Science councils in South Africa. South African Journal of Science 104(3): 435-438.

Sibanda, M. 2009. Intellectual property, commercialisation and institutional arrangements at South Africa's publicly financed research institutions. In The economics of intellectual property in South Africa, ed. D. Kaplan, 113-145. Geneva: World Intellectual Property Organisation.

Sieger, P. and E. Monsen. 2015. Founder, academic, or employee? A nuanced study of career choice intentions. Journal of Small Business Management 53(S1): 30-57.

Tang, J., K. M. M. Kacmar and L. Busenitz. 2012. Entrepreneurial alertness in the pursuit of new opportunities. Journal of Business Venturing 27(1): 77-94.

Uctu, R. and R. Jafta. 2014. Spinning-off or licensing? The case of academic technology transfer at two South African universities. Industry and Higher Education 28(2): 127-141.

Universities SA. 2016. http://www.universitiessa.ac.za/public-universities-south-africa (Accessed 18th September 2016).

Urban, B. 2017. Corporate entrepreneurship in South Africa: The role of organizational factors and entrepreneurial alertness in advancing innovativeness. Journal of Developmental Entrepreneurship 20(3): 1-20.

Urban, B. and J. Chantson. 2018. Academic entrepreneurship in South Africa: Testing for entrepreneurial intentions. Journal of Technology Transfer 38(5): 1-33.

Urban, B. and R. Pendame, R. 2015. Perseverance among university students as an indicator of entrepreneurial intent. South African Journal of Higher Education 29(5): 263-278.

Urbano, D. and M. Guerrero. 2013. Entrepreneurial universities: Socioeconomic impacts of academic entrepreneurship in a European region. Spain: Economic Development Quarterly.

Walter, S. G., K. P. Parboteeah and A. Walter, A. 2013. University departments and self-employment intentions of business students: A cross-level analysis. Entrepreneurship Theory and Practice 37(2): 175-200 